\title{
KEANEKARAGAMAN ANGGREK DI CAGAR ALAM DAN TAMAN WISATA ALAM TELAGA WARNA, PUNCAK, BOGOR
}

\author{
Siti Suryani Tahier ${ }^{1}$, Tri Saptari Haryani ${ }^{1 *}$, Sri Wiedarti $^{1}$ \\ ${ }^{1}$ Program Studi Biologi FMIPA Universitas Pakuan, Bogor \\ "e-mail: trisaptari@unpak.ac.id
}

diterima:26 Juli 2018; direvisi:29 Agustus 2018; disetujui: 5 September 2018

\begin{abstract}
ABSTRAK
Keberadaan anggrek seringkali terancam kepunahan yang dapat disebabkan oleh kerusakan alam. Selain itu, pengambilan anggrek secara terus menerus dari alam tanpa mempertimbangkan kelestariannya dapat mengancam kepunahan anggrek di suatu wilayah. Perlu adanya pengetahuan tentang keanekaragaman anggrek sehingga dapat menjadi dasar konservasi di suatu kawasan khususnya Cagar Alam dan Taman Wisata Alam Telaga Warna Bogor. Penelitian menggunakan metode transek dan pengumpulan data yang dilakukan menggunakan teknik observasi lapangan. Areal pengamatan terdiri dari tiga lokasi ketinggian yaitu 1400, 1500 dan $1600 \mathrm{~m}$ di atas permukaan laut (dpl). Tumbuhan anggrek yang ditemukan sebanyak 27 jenis yang terdiri dari 19 marga. Dari perhitungan Indeks Nilai Penting (INP), ditemukan jenis yang mendominasi di ketinggian 1400 dan $1500 \mathrm{~m}$ dpl adalah Ceratostylis crassifolia, sedangkan di ketinggian dan $1600 \mathrm{~m}$ dpl adalah Liparis compressa. Indeks keanekaragaman jenis di lokasi penelitian dengan ketinggian $1400 \mathrm{~m}$ dpl adalah sedang dan pada ketinggian 1500 dan $1600 \mathrm{~m}$ dpl adalah tinggi. indeks penyebaran diketahui bahwa pola penyebaran jenis tumbuhan anggrek di tiga lokasi penelitian memiliki pola penyebaran mengelompok (clumped).
\end{abstract}

\section{Kata kunci: Keanekaragaman, Anggrek, Telaga Warna \\ DIVERSITY OF ORCHIDS IN NATURE RESERVE AND NATURE PARKS OF TELAGA WARNA COLOR, PUNCAK, BOGOR}

\begin{abstract}
The existence of orchids is often threatened with extinction that can be caused by natural damage. In addition, the continuous harvesting of orchids from nature without considering its sustainability can threaten the extinction of orchids in a region. There is a need for knowledge about the diversity of orchids so that it can be the basis of conservation in a region specifically nature reserve and Nature Park Bogor. Research using transect methods and data collection conducted using field observation techniques. The observation area consists of three locations altitude: 1400, 1500 and $1600 \mathrm{~m}$ above sea level . There are 27 species of orchids consisting of 19 genera. From the calculation of important value index (INP), the dominating type is found at altitude 1400 and $1500 \mathrm{~m}$ above sea level is Ceratostylis crassifolia, While at height and 1600 $\mathrm{m}$ DPL is Liparis compressa. Index diversity of type in the research site with a height of $1400 \mathrm{~m}$ DPL is moderate and at an altitude of 1500 and $1600 \mathrm{~m}$ DPL is high. The spread index is known that the pattern of spreading orchid species in three research locations has a clumped group spread pattern.
\end{abstract}

Keywords: diversity, orchids, Telaga Warna 
PENDAHULUAN

Kekayaan Indonesia dalam keanekaragaman jenis tumbuhan merupakan hal yang patut disyukuri sebagai anugerah dari Sang Maha Pencipta. Irwan (2007) menyatakan bahwa terdapat sekitar 28.000 jenis tumbuhan hidup di Indonesia.

Hal ini menunjukan bahwa tumbuhan yang tumbuh di Indonesia kurang lebih sekitar $10 \%$ dari tumbuhan yang ada di muka Bumi.

Cagar Alam dan Taman Wisata Alam (CATWA) Telaga Warna memiliki status sebagai kawasan konservasi yang berfungsi melindungi keanekaragaman jenis dan sumberdaya genetik (Rohman, 2002). Selain sebagai kawasan konservasi, kawasan CATWA Telaga Warna merupakan kawasan wisata yang sering dikunjungi wisatawan. Keberadaan CATWA Telaga Warna yang sering dikunjungi wisatawan memungkinkan terjadinya interaksi antara masyarakat dan hutan yang cukup tinggi dan dapat mengancam keutuhan potensi flora yang terkandung di dalamnya. Salah satunya yaitu pengambilan tanaman hias seperti anggrek alam (Wiedarti dkk, 2010).

Tumbuhan anggrek merupakan salah satu dari suku tumbuhan yang mempunyai jumlah jenis terbanyak, kurang lebih terdapat 10.000-15.000 jenis yang tersebar di seluruh dunia (Yunaidi dkk, 2003). Di Indonesia terdapat sekitar 5000 jenis anggrek yang tersebar dari Pulau Sumatera hingga Papua. Pulau Kalimantan memiliki sekitar 3.000 jenis anggrek, Pulau Papua memiliki sekitar 1.000 jenis, Pulau Sumatera memiliki sekitar 990 jenis dan Pulau Maluku sebanyak kurang lebih 125 Jenis (Pranata, 2005). Sementara itu, kurang lebih terdapat 731 jenis di Pulau Jawa, 231 jenis diantaranya dinyatakan endemik. Di Jawa Barat sendiri terdapat sebanyak 642 jenis tumbuhan anggrek (Comber, 1990). Akan tetapi, keberadaan anggrek alam sebagai potensi tanaman hias seringkali terancam kepunahan yang dapat disebabkan oleh kerusakan alam. Selain itu, pengambilan anggrek secara terus menerus dari alam tanpa mempertimbangkan kelestariannya akan merugikan keberadaannya karena dapat mengancam kepunahan anggrek di suatu wilayah (Djuita $d k k ., 2004)$.

Menyikapi hal tersebut maka penelitian mengenai keanekaragaman jenis anggrek ini dirasa penting untuk dilakukan sehingga dapat diketahui potensinya dan selanjutnya dapat diusahakan pelestariannya khususnya di Cagar Alam dan Taman Wisata Alam Telaga Warna. Tujuan penelitian ini adalah untuk mengetahui Indeks Nilai Penting (INP), tingkat keanekaragaman jenis dan pola penyebaran tumbuhan anggrek yang terdapat di Cagar Alam dan Taman Wisata Alam Telaga Warna.

\section{BAHAN DAN METODE}

Lokasi penelitian terletak pada ketinggian yaitu 1400, 1500 dan $1600 \mathrm{~m}$ dpl. Identifikasi tumbuhan dilakukan di Laboratorium Biologi Program Studi Biologi Fakultas Matematika dan Ilmu Pengetahuan Alam, Universitas Pakuan dan untuk sampel tumbuhan anggrek yang sulit diidentifikasi, identifikasi dilakukan di Herbarium Bogoriense, LIPI-Cibinong.

Bahan yang digunakan dalam penelitian meliputi tumbuhan anggrek, tali, kompas, meteran, patok, kertas koran, alkohol 70\%, label, kantong plastik, sedangkan alatnya meliputi termometer, altimeter, soil tester, alat tulis, higro meter, teropong binokuler, buku identifikasi jenis dan tabel data pengamatan lapang. Penelitian ini bersifat deskriptif menggunakan metode transek dan pengumpulan data yang dilakukan dengan teknik observasi lapangan.

Pada tiap lokasi penelitian dibuat tiga buah transek (transek a, b dan c) yang diharapkan mewakili tiap ketinggian. Tiap transek terdiri atas 10 petak contoh (plot). Masing-masing petak contoh berukuran $1 \mathrm{x}$ $1 \mathrm{~m}$ dengan jarak antar transek $10 \mathrm{~m}$ pada tiap lokasi penelitian pada ketinggian yang berbeda (Brower et al., 1990). Penentuan petak contoh didasarkan pada kondisi medan yang memadai, aman dan searah dengan jalur transek. 
Parameter yang diamati meliputi kerapatan, frekuensi, Indeks Nilai Penting (INP), indeks keanekaragaman jenis dan pola penyebaran. Adapun pengambilan data meliputi jenis tumbuhan dan jumlah individu pada semua petak contoh. Data hasil pengamatan di lapangan dicatat ke dalam tabel data pengamatan lapangan.

Identifikasi dilakukan dengan cara melakukan pengamatan morfologi tumbuhan. Bagian tanaman yang diamati adalah daun, batang, akar dan bunga, yang dicocokkan dengan buku identifikasi anggrek. Analisis parameter menggunakan rumus sebagai berikut :

Kerapatan atau densitas adalah jumlah individu organisme per satuan ruang. Rumus yang dipakai dalam penentuan kerapatan adalah sebagai berikut (Indriyanto, 2006) :

a) Kerapatan Mutlak (KM)

$$
K M=\frac{\text { jumlah individu }}{\text { luas seluruh petak contoh }}
$$

KM seluruh spesies $=\sum K M$ suatu spesies

b) Kerapatan Relatif (KR)

$$
K R=\frac{K M \text { suatu spesies }}{\text { KM seluruh spesies }} \times 100 \%
$$

Frekuensi adalah jumlah petak contoh ditemukannya suatu jenis dari sejumlah petak contoh yang dibuat. Rumus yang dipakai dalam penentuan frekuensi adalah sebagai berikut (Indriyanto, 2006) :

a) Frekuensi Mutlak (FM)

$$
F M=\frac{\text { jumlah petak ditemukannya suatu spesies }}{\text { jumlah seluruh petak contoh }}
$$

FM seluruh spesies $=\sum$ FM suatu spesies

b) Frekuensi Relatif (FR)

$$
F R=\frac{F M \text { suatu spesies }}{\text { FM seluruh spesies }} \times 100 \%
$$

Jenis-jenis yang dominan dalam suatu komunitas tumbuhan akan memiliki nilai
Indeks Nilai Penting (INP) yang paling tinggi diantara jenis yang lainnya. Rumus yang digunakan untuk menghitung Indeks Nilai Penting (INP) adalah (Indriyanto, 2006):

\section{$I N P=$ Kerapatan relatif + Frekuensi relatif}

Indeks keanekaragaman jenis merupakan parameter vegetasi untuk membandingkan berbagai komunitas tumbuhan, semakin tinggi nilai keanekaragaman jenis menunjukkan semakin baik kondisi komunitas tersebut. Keanekaragaman jenis diketahui dengan indeks keanekaragaman jenis ShannonWienner (Fahrul, 2007). Adapun penentuan tingkat keanekaragaman berdasarkan nilai indeks keanekaragaman jenis ShannonWienner dapat dilihat pada Tabel 1, dan analisis datanya adalah:

$$
H^{\prime}=-\sum \frac{n i}{N} \cdot \frac{\log n i / N}{\log 2}
$$

Keterangan:

H' = Indeks keanekaragaman Shannon-Wienner ni $=$ Jumlah individu dari suatu jenis

$\mathrm{N}=$ Jumlah total individu seluruh jenis

Tabel 1. Penentuan Tingkat Keanekaragaman Jenis Berdasarkan Jenis Shannon-Wienner

\begin{tabular}{cc}
\hline Nilai H' & $\begin{array}{c}\text { Tingkat } \\
\text { Keanekaragaman } \\
\text { Jenis }\end{array}$ \\
\hline$>3$ & Tinggi \\
$1-3$ & Sedang \\
$<1$ & Rendah \\
\hline
\end{tabular}

Pola penyebaran adalah parameter kualitatif yang menggambarkan keberadaan jenis. Pola penyebaran individu di suatu permukaan habitat dapat bersifat seragam (uniform), acak (random) atau mengelompok (clumped). Ketiga kategori pola penyebaran ditentukan dengan cara metode Indeks Morishita (Southwood, 1971) dengan penentuan pola penyebaran seperti pada Tabel 2. Adapun analisis datanya adalah:

$$
I S=N \frac{\sum x^{2}-\sum x}{\left(\sum x\right)^{2}-\sum x}
$$


Keterangan:

IS = Indeks Morishita

$\mathrm{N}=$ Total jenis sampel

$\mathrm{x}=$ Individu jenis

Tabel 2. Penentuan Pola Penyebaran

Berdasarkan Nilai Metode Indeks Morisita

\begin{tabular}{cc}
\hline Nilai IS & Pola Penyebaran \\
\hline$<1$ & Seragam \\
$>1$ & Mengelompok \\
1 & Acak \\
\hline
\end{tabular}

\section{HASIL DAN PEMBAHASAN \\ Jenis Tumbuhan Anggrek}

Hasil penelitian pada tiga lokasi dengan perbedaan ketinggian yaitu 1400, 1500 dan $1600 \mathrm{~m}$ dpl menunjukkan adanya perbedaan jenis tumbuhan anggrek yang ditemukan di setiap lokasi penelitian. Data jenis-jenis anggrek terdapat pada Tabel 3 .

Pada seluruh lokasi penelitian dengan ketinggian berbeda yaitu 1400, 1500 dan $1600 \mathrm{~m}$ dpl dperoleh 27 jenis tumbuhan anggrek yang termasuk dalam 19 marga. 22 jenis termasuk anggrek epifit dan 5 jenis termasuk anggrek teresterial. Pada ketinggian $1400 \mathrm{~m}$ dpl ditemukan sebanyak 13 jenis tumbuhan anggrek yang termasuk dalam 10 marga. Pada lokasi penelitian dengan ketinggian $1500 \mathrm{~m} \mathrm{dpl}$, ditemukan sebanyak 14 jenis anggrek yang termasuk dalam 12 marga. Pada lokasi penelitian dengan ketinggian $1600 \mathrm{~m}$ dpl, ditemukan sebanyak 20 jenis anggrek yang termasuk dalam 15 marga. Banyaknya jenis tumbuhan akan mencerminkan potensi keanekaragaman hayati sekaligus potensi plasma nutfah dalam kawasan tersebut (Indriyanto, 2006).

Pada lokasi ketinggian $1600 \mathrm{~m}$ dpl lebih banyak ditemukan tumbuhan anggrek dibandingkan dengan ketinggian 1400 dan $1500 \mathrm{~m}$ dpl. Hal ini terjadi karena pada ketinggian tersebut, faktor lingkungan yang dibutuhkan untuk hidup bagi tumbuhan anggrek cukup memadai. Anggrek membutuhkan sinar matahari dalam jumlah yang berbeda-beda menurut jenis dan tipe habitatnya. Angin dan curah hujan

berpengaruh terhadap kelembaban lingkungan tumbuh anggrek. Tanaman anggrek tidak cocok dalam suasana basah terus menerus, akan tetapi menyukai kelembaban udara $60-80 \%$ di siang hari dan 59-60\% pada malam hari (Gunadi, 1977). Di antara beberapa ketinggian lokasi tersebut, pada ketinggian $1600 \mathrm{~m}$ dpl persentasi kelembaban yang paling rendah yaitu sebesar $88 \%$. Sehingga, beragam jenis anggrek lebih banyak ditemukan pada ketinggian $1600 \mathrm{~m}$ dpl.

Tabel 3. Jenis-jenis Tumbuhan Anggrek di Ketinggian 1400, 1500 dan 1600 m dpl

\begin{tabular}{|c|c|c|c|}
\hline \multirow[t]{2}{*}{ Jenis } & \multicolumn{3}{|c|}{$\begin{array}{c}\text { Jumlah individu } \\
\text { perketinggian (m dpl) }\end{array}$} \\
\hline & 1400 & 1500 & 1600 \\
\hline $\begin{array}{l}\text { Agrostophyllum } \\
\text { cyathiforme }\end{array}$ & 8 & 11 & 14 \\
\hline $\begin{array}{l}\text { Anoestochillus } \\
\text { reinwardtii }\end{array}$ & 8 & 18 & 22 \\
\hline Appendicula alba & 14 & 9 & - \\
\hline Appendicula angustifolia & 12 & 6 & - \\
\hline Bulbophyllum flavescens & - & 9 & 12 \\
\hline Bulbophyllum lobii & - & - & 5 \\
\hline $\begin{array}{l}\text { Bulbophyllum } \\
\text { ovalifolium }\end{array}$ & - & - & 1 \\
\hline Ceratostylis crassifolia & 31 & 32 & 24 \\
\hline Cryptostylis javanica & - & 19 & 14 \\
\hline Coelogyne miniata & - & - & 2 \\
\hline Dendrobium mutabile & 11 & - & - \\
\hline Dendrochilum eduntulum & - & 7 & 10 \\
\hline Dendrochilum sp. & - & - & 3 \\
\hline $\begin{array}{l}\text { Epigenium triflorum var. } \\
\text { triflorum }\end{array}$ & - & 5 & 19 \\
\hline $\begin{array}{l}\text { Epigenium triflorum var. } \\
\text { elongatum }\end{array}$ & - & - & 18 \\
\hline Eria multiflora & 7 & 12 & 7 \\
\hline Eria sp. & 8 & - & - \\
\hline Flickingeria aureiloba & 21 & 15 & - \\
\hline Liparis compressa & 25 & 32 & 29 \\
\hline Liparis montana & - & 12 & 20 \\
\hline Malleola sp. & - & - & 6 \\
\hline $\begin{array}{l}\text { Paphiopedillum } \\
\text { javanicum }\end{array}$ & - & - & 3 \\
\hline Pheretia laxiflora & 2 & - & - \\
\hline Rubiquetia spatulata & - & - & 1 \\
\hline Schoenorchis junctifolia & 14 & 9 & 14 \\
\hline Thrixpermum anceps & 1 & - & - \\
\hline $\begin{array}{l}\text { Thrixpermum } \\
\text { purparascens }\end{array}$ & - & - & 3 \\
\hline Total & 162 & 186 & 227 \\
\hline
\end{tabular}


Pada kawasan CATWA Telaga Warna dengan 3 lokasi ketinggian yang berbeda yaitu 1400, 1500 dan $1600 \mathrm{~m}$ dpl menunjukan perbedaan ditemukannya anggrek yang ada di kawasan tersebut. Wiharto (2009) menyatakan bahwa perbedaan ketinggian tempat akan mempengaruhi keadaan lingkungan tumbuh tumbuhan terutama suhu, kelembaban, intensitas sinar matahari dan keadaan tanah sehingga keadaan lingkungan tumbuh yang mempengaruhi pertumbuhan. Sementara itu, Arief (2001) menyatakan bahwa hutan sebagai tempat tumbuhnya tumbuhan tidak lepas dari faktor-faktor yang mempengaruhinya, termasuk di dalamnya adalah faktor lingkungan.

Terdapat 6 jenis tumbuhan anggrek ditemukan di ketiga ketinggian lokasi yang berbeda yaitu jenis Agrostophyllum cyathiforme, Anoestochillus reinwardtii, Ceratostylis crassifolia, Eria multiflora, Liparis compressa dan Schoenorchis junctifolia. Selain itu, terdapat 3 jenis tumbuhan anggrek yang ditemukan pada dua lokasi penelitian di ketinggian 1400 dan $1500 \mathrm{~m}$ dpl yaitu Appendicula alba, Appendicula angustifolia dan Flickingeria aureiloba. Tumbuhan anggrek yang ditemukan pada ketinggian 1500 dan 1600 m dpl terdapat 3 jenis yaitu Bulbophyllum flavescens, Cryptostylis javanica dan Dendrochillum eduntulum. Hal ini menunjukkan bahwa jenis-jenis tersebut mampu beradaptasi pada lokasi ketinggian yang berbeda.

\section{Kerapatan, Frekuensi dan Indeks Nilai Penting (INP) Tumbuhan Anggrek}

Kerapatan, frekuensi dan Indeks Nilai Penting (INP) setiap anggrek pada ke-3 ketinggian berbeda-beda, yang tersaji pada Tabel 4.
Tabel 4. Nilai Kerapatan Relatif (KR), Frekuensi Relatif (FR) dan Indeks Nilai Penting (INP) Tumbuhan Anggrek di Ketinggian 1400, 1500 dan $1600 \mathrm{~m} \mathrm{dpl}$

\begin{tabular}{|c|c|c|c|c|}
\hline $\begin{array}{l}\text { Lokasi } \\
\text { (m dpl) }\end{array}$ & Jenis & $\begin{array}{l}\text { KR } \\
(\%)\end{array}$ & $\begin{array}{l}\text { FR } \\
(\%)\end{array}$ & $\begin{array}{l}\text { INP } \\
(\%)\end{array}$ \\
\hline \multirow{14}{*}{1400} & $\begin{array}{l}\text { Agrostophyllum } \\
\text { cyathiforme }\end{array}$ & 4,99 & 5,16 & 10,15 \\
\hline & $\begin{array}{l}\text { Anoestochillus } \\
\text { reinwardtii }\end{array}$ & 4,99 & 7,93 & 12,92 \\
\hline & Appendicula alba & 8.67 & $\begin{array}{c}11,9 \\
0\end{array}$ & 20,57 \\
\hline & $\begin{array}{l}\text { Appendicula } \\
\text { angustifolia }\end{array}$ & 7,38 & 7,93 & 15,31 \\
\hline & $\begin{array}{l}\text { Ceratostylis } \\
\text { crassifolia }\end{array}$ & 19,00 & $\begin{array}{l}17,0 \\
6\end{array}$ & 36,06 \\
\hline & Dendrobium mutabile & 6,82 & 6,75 & 13,57 \\
\hline & Eria multiflora & 4,25 & 3,97 & 8,22 \\
\hline & Eria sp. & 4,99 & 3,97 & 8,96 \\
\hline & Flickingeria aureiloba & 12,91 & $\begin{array}{l}11,9 \\
0\end{array}$ & 24,81 \\
\hline & Liparis compressa & 15,49 & $\begin{array}{l}15,8 \\
8\end{array}$ & 31,37 \\
\hline & Pheretia laxiflora & 1,29 & 2,39 & 3,68 \\
\hline & $\begin{array}{l}\text { Schoenorchis } \\
\text { junctifolia }\end{array}$ & 8,67 & 3,97 & 12,64 \\
\hline & Thrixpermum anceps & 0,55 & 1,19 & 1,74 \\
\hline & Total & 100 & 100 & 200 \\
\hline $\begin{array}{l}\text { Lokasi } \\
\text { (m dpl) }\end{array}$ & Jenis & $\begin{array}{l}\text { KR } \\
(\%)\end{array}$ & $\begin{array}{l}\text { FR } \\
(\%)\end{array}$ & $\begin{array}{l}\text { INP } \\
(\%) \\
\end{array}$ \\
\hline \multirow{13}{*}{1500} & Appendicula alba & 4,87 & 4,14 & 9,01 \\
\hline & $\begin{array}{l}\text { Appendicula } \\
\text { angustifolia }\end{array}$ & 3,24 & 2,69 & 5,93 \\
\hline & $\begin{array}{l}\text { Bulbophyllum } \\
\text { flavescens }\end{array}$ & 4,87 & 5,39 & 10,26 \\
\hline & $\begin{array}{l}\text { Ceratostylis } \\
\text { crassifolia }\end{array}$ & 17,17 & 16,59 & 33,76 \\
\hline & Cryptostylis javanica & 10,21 & 9,54 & 19,75 \\
\hline & $\begin{array}{l}\text { Dendrobium } \\
\text { eduntulum }\end{array}$ & 3,72 & 4,78 & 8,50 \\
\hline & $\begin{array}{l}\text { Epigenium triflorum } \\
\text { var. triflorum }\end{array}$ & 2,59 & 2,69 & 5,28 \\
\hline & Eria multiflora & 6,47 & 7,46 & 13,93 \\
\hline & Flickingeria aureiloba & 8,10 & 6,25 & 14,35 \\
\hline & Liparis compressa & 11,83 & 13,07 & 24,09 \\
\hline & Liparis montana & 6,49 & 6,25 & 12,74 \\
\hline & $\begin{array}{l}\text { Schoenorchis } \\
\text { junctifolia }\end{array}$ & 4,87 & 4,78 & 9,65 \\
\hline & Total & 100 & 100 & 200 \\
\hline \multirow{14}{*}{1600} & $\begin{array}{l}\text { Agrostophyllum } \\
\text { cyathiforme }\end{array}$ & 6,13 & 7,94 & 14,02 \\
\hline & $\begin{array}{l}\text { Anoestochillus } \\
\text { reindwardtii }\end{array}$ & 9,74 & 9,79 & 19,53 \\
\hline & $\begin{array}{l}\text { Bulbophyllum } \\
\text { flavescens }\end{array}$ & 5,34 & 4,81 & 10,15 \\
\hline & Bulbophyllum lobii & 2,13 & 1,10 & 3,23 \\
\hline & $\begin{array}{l}\text { Bulbophyllum } \\
\text { ovalifolium }\end{array}$ & 0,40 & 0,55 & 0,95 \\
\hline & $\begin{array}{l}\text { Ceratostylis } \\
\text { crassifolia }\end{array}$ & 10,67 & 9,79 & 20,46 \\
\hline & Cryptostylis javanica & 6,13 & 5,54 & 11,67 \\
\hline & Coelogyne miniata & 0,80 & 1,10 & 1,9 \\
\hline & $\begin{array}{l}\text { Dendrochilum } \\
\text { eduntulum }\end{array}$ & 4,40 & 4,99 & 9,39 \\
\hline & Dendrochilum sp. & 1,33 & 1,84 & 3,17 \\
\hline & $\begin{array}{l}\text { Epigenium triflorum } \\
\text { var. triflorum }\end{array}$ & 8,40 & 7,94 & 16,34 \\
\hline & $\begin{array}{l}\text { Epigenium triflorum } \\
\text { var. elongatum }\end{array}$ & 8,00 & 9,79 & 17,79 \\
\hline & Eria multiflora & 3,07 & 3,69 & 6,76 \\
\hline & Liparis compressa & 12,80 & 11,09 & 23,89 \\
\hline
\end{tabular}


Siti Suryani Tahier, dkk: Anggrek di Cagar Alam dan Taman Wisata Alam ...

\begin{tabular}{lllll}
\hline & Liparis montana & 8,80 & 10,35 & 19,15 \\
\hline $\begin{array}{llll}\text { Malleola } \text { sp. } \\
\begin{array}{l}\text { Paphiopedillum } \\
\text { javanicum }\end{array}\end{array}$ & 2,67 & 1,11 & 3,77 \\
\hline $\begin{array}{l}\text { Rubiquetia spatulata } \\
\begin{array}{l}\text { Schoenorchis } \\
\text { junctifolia }\end{array}\end{array}$ & 0,40 & 0,55 & 1,88 \\
\hline $\begin{array}{l}\text { Thrixpermum } \\
\text { purparascens }\end{array}$ & 6,13 & 5,54 & 11,67 \\
\hline Total & $\mathbf{1 0 0}$ & $\mathbf{1 0 0}$ & $\mathbf{2 0 0}$ \\
\hline
\end{tabular}

\section{Kerapatan}

Nilai Kerapatan Relatif (KR) tinggi pada jenis tumbuhan anggrek merupakan jenis tumbuhan dengan jumlah individu lebih banyak dalam suatu unit luas, sedangkan jenis tumbuhan anggrek dengan nilai Kerapatan Relatif (KR) rendah memiliki jumlah individu yang lebih sedikit. Hal ini dipengaruhi oleh kondisi lingkungan sekitar, serta adanya persaingan antar jenis dalam mendapatkan ruang, nutrisi dan cahaya. Nilai Kerapatan Relatif diperlukan untuk menetapkan Indeks Nilai Penting suatu jenis tumbuhan.

Pada Tabel 4 dapat dilihat bahwa pada ketinggian $1400 \mathrm{~m}$ dpl nilai Kerapatan Relatif berkisar antara 0,55\%-19,00\%. Adapun jenis tumbuhan anggrek yang memiliki nilai Kerapatan Relatif tertinggi yaitu Ceratostylis crassifolia sebesar $19,00 \%$ dengan jumlah sebanyak 31 individu/30 $\mathrm{m}^{2}$ atau 31 individu dari 30 petak contoh. Ceratostylis crassifolia merupakan anggrek endemik Jawa. Kondisi lingkungan yang sesuai baik itu suhu ataupun kelembapan akan sangat mendukung tumbuhnya anggrek jenis ini (Comber, 1990). Adapun jenis tumbuhan anggrek yang memiliki nilai Kerapatan Relatif terendah adalah Thrixpermum anceps sebesar $0,55 \%$ dengan jumlah sebanyak 1 individu/30 $\mathrm{m}^{2}$. Warsita, dkk (2003) menyatakan bahwa Thrixpermum anceps dapat tumbuh di hutan primer hingga ketinggian $1520 \mathrm{~m}$ dpl. Namun, nilai kerapatan yang rendah pada jenis anggrek ini dapat terjadi karena adanya persaingan antar jenis dalam mendapatkan ruang, nutrisi dan cahaya.

Pada ketinggian $1500 \mathrm{~m}$ dpl, nilai Kerapatan Relatif berkisar antara 2,59\%$17,17 \%$. Adapun jenis tumbuhan anggrek yang memiliki nilai Kerapatan Relatif tertinggi adalah Ceratostylis crassifolia dengan nilai sebesar $17,17 \%$ dan ditemukan sebanyak 32 individu/30 $\mathrm{m}^{2}$. Hal ini dikarenakan Ceratostylis crassifolia dapat tumbuh hingga pada ketinggian $1600 \mathrm{~m}$ dpl (Warsita, dkk, 2003). Selain itu, faktor lingkungan lainnya yang dapat mendukung kelangsungan hidup jenis anggrek tersebut, salah satunya yaitu suhu yang cukup memadai. Anggrek ini tumbuh baik pada temperatur siang antara $15-21^{\circ} \mathrm{C}$. Jenis tumbuhan anggrek dengan nilai terendah yaitu Epigenium triflorum var. triflorum yang ditemukan sebanyak 5 individu $/ 30 \mathrm{~m}^{2}$ dengan nilai Kerapatan Relatif masingmasing sebesar 2,59\%.

Pada ketinggian $1600 \mathrm{~m}$ dpl, nilai Kerapatan Relatif berkisar antara 0,40\%$12,80 \%$. adapun jenis dengan nilai kerapatan tertinggi yaitu Liparis compressa sebanyak 29 individu/30 $\mathrm{m}^{2}$ dengan nilai Kerapatan Relatif sebesar 12,80\%. Anggrek jenis ini dapat tumbuh di berbagai tempat dengan perbedaan suhu (Comber, 1990). Jadi cara hidupnya sangat mudah beradaptasi dengan lingkungan yang ada. Jenis dengan nilai kerapatan terendah yaitu Bulbophyllum ovalifolium dan Rubiquetia spatulata yang ditemukan masing-masing sebanyak 1 individu/30 $\mathrm{m}^{2}$ dengan nilai sebesar $0,40 \%$. Bulbophyllum ovalifolium sering ditemukan di pegunungan yang lembab hingga ketinggian $2500 \mathrm{~m}$ dpl (Puspaningtyas $d k k$., 2003). Namun, nilai kerapatan yang rendah pada jenis anggrek ini dapat terjadi karena adanya persaingan antar jenis dalam mendapatkan ruang, nutrisi dan cahaya. Adapun anggrek jenis Rubiquetia spatulata meskipun nilai kerapatan relatifnya rendah, yaitu sebesar $0,40 \%$ tapi menunjukkan bahwa anggrek jenis Rubiquetia spatulata mampu beradaptasi sampai di ketinggian $1600 \mathrm{~m}$ dpl. Warsita, dkk (2003) menyatakan bahwa Rubiquetia spatulata umumnya hidup sampai ketinggian $1000 \mathrm{~m}$ dpl. 


\section{Frekuensi}

Nilai Frekuensi Relatif (FR) tinggi pada suatu jenis tumbuhan, menunjukkan tingkat penguasaan jenis tumbuhan tersebut lebih dominan dibanding jenis tumbuhan lainnya. Sama halnya dengan nilai Kerapatan Relatif, nilai Frekuensi Relatif diperlukan untuk menetapkan Indeks Nilai Penting suatu jenis tumbuhan.

Berdasarkan Tabel 4, nilai Frekuensi Relatif pada lokasi penelitian di ketinggian $1400 \mathrm{~m}$ dpl berkisar antara 1,19\%-19,00\%. Ceratostylis crassifolia mempunyai nilai Frekuensi Relatif tertinggi yaitu sebesar $17,06 \%$. Hal ini terjadi karena Ceratostylis crassifolia sangat baik untuk tumbuh pada temperatur antara $15-21^{\circ} \mathrm{C}$. Kondisi lingkungan yang sesuai baik itu suhu ataupun kelembapan akan sangat mendukung tumbuhnya anggrek jenis ini (Comber, 1990) sehingga sering sekali ditemukan dalam petak contoh yaitu sebanyak 13 dari 30 petak contoh yang ada pada ketinggian $1400 \mathrm{~m}$ dpl. Sedangkan Thrixpermum anceps mempunyai nilai Frekuensi Relatif terendah yaitu sebesar $0,55 \%$. Adanya persaingan antar jenis dalam mendapatkan ruang, nutrisi dan cahaya menjadikan anggrek jenis ini sangat sedikit ditemukan pada petak contoh yaitu 1 dari 30 petak contoh pada ketinggian $1400 \mathrm{~m}$ dpl.

Pada lokasi penelitian di ketinggian $1500 \mathrm{~m}$ dpl berkisar antara 2,69\%-16,59\%. Ceratostylis crassifolia memiliki nilai Frekuensi Relatif tertinggi yaitu sebesar $16,59 \%$. Hal ini terjadi karena anggrek Ceratostylis crassifolia sangat baik untuk tumbuh pada temperatur antara $15-21^{\circ} \mathrm{C}$. Kondisi lingkungan yang sesuai baik itu suhu ataupun kelembapan akan sangat mendukung tumbuhnya anggrek ini (Comber, 1990). Sehinggga, Ceratostylis crassifolia sering sekali ditemukan dalam petak contoh yaitu sebanyak 24 dari 30 petak contoh yang ada pada ketinggian 1500 m dpl. Sementara itu nilai Frekuensi Relatif terendah dimiliki oleh Appendicula angustifolia dan Epegenium triflorum var. triflorum yaitu masing-masing sebesar $2,69 \%$ sehingga sangat sedikit ditemukan pada petak contoh yaitu 4 dari 30 petak contoh pada ketinggian $1500 \mathrm{~m}$ dpl. Comber (1990) menyatakan bahwa Appendicula angustifolia umum ditemukan di Pulau Jawa pada ketinggan 700-1700 m dpl. Namun, nilai frekuensi relatif yang rendah dapat terjadi karena adanya persaingan untuk mendapatkan nutrisi.

Pada lokasi penelitian dengan ketinggian $1600 \mathrm{~m}$ dpl nilai Frekuensi Relatif berkisar antara 0,55\%-11,09 \%. Liparis compressa memiliki nilai Frekuensi Relatif tertinggi yaitu sebesar 11,09\%. Hal ini terjadi karena Liparis compressa sering sekali ditemukan dalam petak contoh yaitu sebanyak 18 dari 30 petak contoh yang ada pada ketinggian $1600 \mathrm{~m}$ dpl. Liparis compressa memiliki nilai Frekuensi Relatif tertinggi pada ketinggian $1600 \mathrm{~m}$ dpl karena lingkungan yang sesuai untuk tempat tumbuh Liparis compressa. Anggrek Liparis compressa dapat umumnya sering ditemukan di hutan primer dan hidup pada ketinggian 700-1800 m dpl di hutan seluruh Jawa. Bahkan keberadaannya dapat pula ditemukan di Sumatera, sulawesi, Kalimantan, semenanjung Malaysia hingga Filipina (Comber, 1990). Sementara itu nilai Frekuensi Relatif terendah dimiliki oleh Bulbophyllum ovalifolium, Paphiopedillum javanicum dan Robiquetia spatulata yaitu masing-masing sebesar $0,55 \% \%$ oleh karena itu, sangat sedikit ditemukan pada petak contoh yaitu 1 dari 30 petak contoh pada ketinggian $1600 \mathrm{~m}$ dpl. Bulbophyllum ovalifolium sering ditemukan di pegunungan yang lembab hingga ketinggian $2500 \mathrm{~m}$ dpl (Puspaningtyas $d k k .$, 2003). Namun, nilai frekuensi relatif yang rendah pada jenis anggrek ini dapat terjadi karena adanya persaingan antar jenis dalam mendapatkan ruang, nutrisi dan cahaya. Adapun anggrek jenis Rubiquetia spatulata meskipun nilai kerapatan relatifnya rendah, yaitu sebesar $0,40 \%$ tapi menunjukkan bahwa anggrek jenis Rubiquetia spatulata mampu beradaptasi sampai di ketinggian $1600 \mathrm{~m}$ dpl. Warsita, dkk (2003) menyatakan bahwa Rubiquetia spatulata umumnya hidup sampai ketinggian $1000 \mathrm{~m}$ dpl. 
Indeks Nilai Penting (INP)

Indeks Nilai Penting (INP) adalah parameter kuantitatif yang digunakan untuk menyatakan tingkat dominansi atau penguasaan jenis-jenis dalam suatu komunitas tumbuhan. Semakin besar tingkat penguasaan suatu jenis dalam suatu komunitas maka Indeks Nilai Penting yang dimiliki jenis tersebut akan semakin besar. Indeks Nilai Penting merupakan penjumlahan dari Kerapatan Relatif dan Frekuensi relatif. Pada Tabel 4 dapat diketahui bahwa tingkat penguasaan tiaptiap jenis tumbuhan anggrek berbeda pada tiap ketinggian.

Jenis anggrek yang mempunyai Indeks Nilai Penting (INP) tertinggi di lokasi dengan ketinggian $1400 \mathrm{~m}$ dpl adalah Ceratostylis crassifolia dengan nilai INP sebesar 36,06\%. Pada ketinggian $1500 \mathrm{~m}$ $\mathrm{dpl}$, Ceratostylis crassifolia dengan INP sebesar 33,76\%. Hal ini menunjukkan bahwa Ceratostylis crassifolia merupakan anggrek yang paling mendominasi di ketinggian 1400 dan $1500 \mathrm{~m}$ dpl. Pada ketinggian $1600 \mathrm{~m}$ dpl Liparis compressa merupakan anggrek yang paling mendominasi dengan nilai INP sebesar $23,89 \%$. Liparis compressa merupakan tumbuhan anggrek yang umumnya sering ditemukan di hutan-hutan yang ada di Pulau Jawa. Anggrek jenis ini dapat tumbuh di berbagai tempat dengan perbedaan suhu (Comber, 1990). Selain jenis Ceratostylis crassifolia dan Liparis compressa, pada ketinggian $1400 \mathrm{~m}$ dpl anggrek Flickingeria aureiloba memiliki nilai INP yang tinggi yaitu sebesar $24,81 \%$ dan mampu beradaptasi hingga ketinggian $1400 \mathrm{~m}$ dpl. Warsita, dkk (2003) menyatakan bahwa anggrek jenis Flickingeria aureiloba tumbuh sampai ketinggian $1000 \mathrm{~m}$ dpl.

Pada ketinggian $1500 \mathrm{~m}$ dpl jenis yang memiliki nilai INP tinggi adalah Cryptostylis javanica sebesar 19,75\%. Anggrek ini merupakan anggrek endemik Jawa yang tumbuh pada lapisan tanah yang berhumus dengan $\mathrm{pH}$ 6,3 dan tumbuh sampai ketinggian $1600 \mathrm{~m}$ dpl (Fizridiyanto dkk, 2000). Pada ketinggian $1600 \mathrm{~m} \mathrm{dpl,}$ anggrek Anoestochilus reindwartii memiliki nilai INP yang tinggi yaitu sebesar $19,53 \%$. Anoestochilus reindwartii umumnya sering ditemukan di hutan primer yang ada di Jawa Barat dan Jawa Timur. Akan tetapi memiliki penyebaran yang luas pula mencapai Sumatera, Kalimantan dan Ambon. Beberapa jenis anggrek mampu beradaptasi sesuai kondisi sehingga dapat tumbuh dengan daerah persebaran yang luas (Puspaningtyas dkk., 2003). Muhammad (2009) menyatakan bahwa perbedaan ketinggian tempat akan mempengaruhi keadaan lingkungan tumbuh tumbuhan terutama suhu, kelembaban, intensitas sinar matahari dan keadaan tanah sehingga keadaan lingkungan tumbuh yang mempengaruhi pertumbuhan.

Persaingan yang terjadi antar jenis maupun sesama jenis disebabkan masingmasing jenis tumbuhan itu mencoba menempati relung ekologi yang sama. Persaingan antar jenis terjadi lebih kuat dibandingkan persaingan sesama jenis, sehingga hanya anggota jenis yang paling tahan bersainglah yang dapat bertahan hidup (Indriyanto, 2006).

\section{Indeks Keanekaragaman Jenis Tumbuhan Anggrek}

Berdasarkan hasil perhitungan indeks keanekaragaman jenis Shannon-Wienner terhadap tumbuhan anggrek pada lokasi penelitian $1400 \mathrm{~m} \mathrm{dpl}$ adalah sedang. Adapun pada lokasi ketinggian 1500 dan $1600 \mathrm{~m} \mathrm{dpl}$, dapat dikategorikan dalam keanekaragaman tinggi. Untuk lebih jelas dapat dilihat pada Tabel 5.

Tabel 5. Indeks Keanekaragaman Jenis Anggrek di Ketinggian 1400, 1500 dan 1600

\begin{tabular}{ccc} 
m dpl & \\
\hline $\begin{array}{c}\text { Lokasi } \\
(\mathbf{m} \text { dpl })\end{array}$ & $\begin{array}{c}\text { Nilai Indeks } \\
\text { Keanekaragaman } \\
\text { Jenis }\left(\mathbf{H}^{\prime}\right)\end{array}$ & $\begin{array}{c}\text { Tingkat } \\
\text { Keanekaragaman } \\
\text { Jenis }\end{array}$ \\
\hline 1400 & 2,99 & Sedang \\
1500 & 3,56 & Tinggi \\
1600 & 3,76 & Tinggi \\
\hline
\end{tabular}


Pada Tabel 5 dapat dilihat bahwa setiap lokasi ketinggian berbeda menunjukan adanya nilai Indeks Keanekaragaman Jenis yang berbeda beda. Akan tetapi, dapat dilihat pula bahwa semakin tinggi lokasi penelitian maka semakin tinggi pula nilai Indeks Keanekaragaman Jenisnya. Puspaningtyas (2005) menyatakan bahwa habitat yang cocok untuk tempat hidup anggrek adalah dataran tinggi karena keragaman jenisnya lebih banyak dibanding dataran rendah.

Keanekaragaman jenis yang tinggi menunjukkan bahwa suatu komunitas memiliki kompleksitas yang tinggi karena interaksi yang terjadi dalam komunitas tersebut sangat tinggi. Tingkat keanekaragaman jenis yang tinggi dimiliki oleh lokasi dengan ketinggian 1500 dan $1600 \mathrm{~m} \mathrm{dpl}$, hal ini diduga karena wilayah CATWA Telaga Warna ini masih tergolong alami sehingga kondisi lingkungan cukup untuk mendukung pertumbuhan anggrek (Maisyaroh, 2010). Anggrek tumbuh di hutan primer yang sangat rentan akan perubahan lingkungan karena ketergantungan anggrek akan lingkungan sangatlah tinggi, maka keberadaan di alam pun sangat tergantung dengan keutuhan komponen penyusun hutan tersebut. Jika komponen-komponen hutan mengalami kerusakan maka akan mempengaruhi kelestarian anggrek di dalamnya (Fizridiyanto dkk, 2000).

Suasana sejuk dan lembab di hutan menjadi suatu habitat yang sesuai untuk tumbuhnya berbagai jenis anggrek. Hal ini sesuai dengan kondisi lingkungan yang ada di kawasan CATWA Telaga Warna yaitu dengan suhu rata $16-28^{\circ} \mathrm{C}$ (Dinas Kehutanan, 2007). Adapun kelembaban pada lokasi berkisar antara $85-90 \%$ yang mendukung pertumbuhan anggrek di kawasan tersebut, hal ini sesuai dengan pernyataan Pranata (2005) bahwa kelembaban yang paling baik untuk pertumbuhan anggrek tidak kurang dari $70 \%$.

\section{Indeks Penyebaran Tumbuhan Anggrek}

Hasil perhitungan indeks penyebaran dengan metode Indeks Morishita, tumbuhan anggrek menyatakan bahwa pola penyebaran tumbuhan anggrek di CATWA Telaga Warna pada ketinggian 1400, 1500 dan $1600 \mathrm{~m}$ dpl menunjukkan pola penyebaran mengelompok (clumped), selengkapnya dapat dilihat pada Tabel 6 .

Tabel 6. Indeks Penyebaran Tumbuhan Anggrek di Ketinggian 1400, 1500 dan 1600

\begin{tabular}{ccc}
\multicolumn{3}{c}{ m dpl } \\
\hline $\begin{array}{c}\text { Lokasi } \\
(\mathbf{m} \\
\mathbf{d p l})\end{array}$ & $\begin{array}{c}\text { Nilai } \\
\text { Indeks } \\
\text { Penyebaran }\end{array}$ & $\begin{array}{c}\text { Pola } \\
\text { Penyebaran }\end{array}$ \\
\hline 1400 & 1,37 & Mengelompok \\
1500 & 1,21 & Mengelompok \\
1600 & 1,45 & Mengelompok \\
\hline
\end{tabular}

Pola peyebaran mengelompok dapat meningkatkan kompetisi dalam meraih unsur hara, ruang dan cahaya. Tumbuhan yang tumbuh secara berkelompok memungkinkan terjadinya kompetisi yang kuat dibandingkan tumbuhan tersebut tumbuh terpisah. Tumbuhan yang tumbuh dalam kelompok tersebut lebih tahan terhadap pengaruh angin yang kencang, sehingga dapat mengendalikan kelembapan udara dan mampu mengendalikan sendiri iklim setempat (Arief, 1994).

Pola penyebaran mengelompok pada suatu populasi merupakan distribusi yang umum terjadi di lapangan. Salah satu faktor yang menyebabkan terjadinya pola penyebaran yang mengelompok adalah adanya perbedaan kondisi lingkungan yang menghasilkan perbedaan dalam habitat yang penting bagi setap organisme yang ada di dalamnya karena suatu organisme akan ada pada suatu area yang faktor-faktor ekologinya tersedia dan sesuai bagi kehidupannya (Indriyanto, 2006). 


\section{KESIMPULAN}

Berdasarkan hasil penelitian, pada seluruh lokasi penelitian dengan ketinggian berbeda yaitu 1400, 1500 dan $1600 \mathrm{~m}$ dpl dperoleh 27 jenis tumbuhan anggrek yang termasuk dalam 19 marga, 22 jenis termasuk anggrek epifit dan 5 jenis termasuk anggrek teresterial. Jenis yang mendominasi pada ketinggian 1400 dan $1500 \mathrm{~m}$ dpl adalah Ceratostylis crassifolia dan pada ketinggian 1600 m dpl adalah Liparis compressa. Nilai indeks keanekaragaman jenis berbeda pada setiap lokasi ketinggian. Pada ketinggian 1400 termasuk kategori sedang dan pada ketinggian 1500 dan $1600 \mathrm{~m}$ dpl termasuk kategori tinggi. Pola penyebaran jenis tumbuhan anggrek pada ketiga lokasi termasuk dalam kategori mengelompok.

\section{DAFTAR PUSTAKA}

Arief, A. (1994). Hutan Hakikat dan Pengaruhnya terhadap Lingkungan. Jakarta: Yayasan Obor Indonesia.

Arief, A. (2001). Hutan dan Kehutanan. Yogyakarta: Penerbit Kanisius.

Brower, James E., Jerrold H. Zar and Carl N. von Ende. (1990). Field and Laboratory Methods for General Ecology Third Edition. Wm. C. Brown Publishers. Dubuque. hlm. 81.

Comber, J.B. (1990). Orchids of Java. Bentham-Moxon Trust, The Royal Botanic Gardens, Kew. hlm. 3-340.

Dinas Kehutanan. (2007). Cagar Alam dan Taman Wisata Alam Telaga Warna. http://dishut.jabarprov.go.id/. Diakses tanggal 24 Februari 2012.

Djuita N.R., Sudarmiyati, S., Candra H., Sarifah, Nurlaiali S., Fathony, R. (2004). Keanekaragaman Anggrek di Situ Gunung Sukabumi. Jurnal Biodiversitas. 5(2): 77-80.

Fahrul, M.F. (2007). Metode Sampling Bioekologi. PT. Bumi Aksara : Jakarta. hlm. 29-45.

Fizridiyanto, I.A, Hidayat, S. (2000). Tinjauan Taksonomi, Potensi dan Konservasi Anggrek Tanah di Taman Nasional Gunung Halimun, Jawa Barat. Prosiding Seminar Sehari Cinta Puspa dan Satwa Nasional. UPT Balai Pengembangan Kebun Raya. LIPI : Bogor. hlm. 281-293.

Gunadi, T. (1977). Seri anggrek No. 1 Mengenali Anggrek Dasar-dasar Perawatan dan Pemeliharaan. Bandung: Perhimpunan anggrek Indonesia.

Indriyanto. (2006). Ekologi Hutan. Jakarta: Bumi Aksara.

Irwan, Z.D. (2007). Prinsip-Prinsip Ekologi Ekosistem, Lingkungan dan Pelestariannya. Jakarta: Bumi Aksara.

Maisyaroh, W. (2010). Struktur Komunitas Tumbuhan Penutup Tanah di Taman Hutan Raya R. Soerjo Cangar, Malang. Jurnal Pembangunan dan Alam Lestari. 1 (1): 1-8.

Parnata, A.S. (2005). Panduan dan Budidaya Perawatan Anggrek. Jakarta: AgroMedia Pustaka.

Puspitaningtyas D.M., Mursidawati S., Sutrisno, Asikin J. (2003). Anggrek Alam di Kawasan Konservasi Pulau Jawa. Pusat Konservasi Tumbuhan Kebun Raya Bogor LIPI : Bogor. hlm. 1-7.

Puspaningtyas D.M. (2005). Studi Keragaman Anggrek di Cagar Alam Gunung Simpang, Jawa Barat. Jurnal Biodiversitas. 6(2): 103-107.

Rohman, A.S. (2002). Keanekaragaman Burung di Cagar Alam dan Taman Wisata Alam Telaga Warna, Puncak. Bogor. Ekologia. 2 (2): 22-26.

Southwood, T.R.E. (1971). Ecological Methods. Chapman and Hall : London. hlm. 37.

Warsita, U., Sadili, A. (2003). Jenis-jenis Anggrek di Taman Nasional Gunung Halimun Salak. Bogor: Biodiversity Conservation Project LIPI-JICAPHKA.

Wiedarti, S., Setiawan, I. (2010). Studi Interaksi Tumbuhan Marga Ficus, Burung dan Mamalia di Cagar Alam dan Taman Wisata Alam Telaga warna, Puncak, Jawa Barat. Jurnal Ekologia. 10(2): 1-6. 
Wiharto, M. (2009). Klasifikasi Vegetasi Zona Sub Pegunungan Gunung Salak, Bogor, Jawa Barat. Disertasi. Sekolah Pascasarjana IPB : Bogor.

Yunaidi, Nurainas. (2003). Jenis-jenis Tumbuhan Anggrek di Taman Nasional Siberut. Padang: Balai Taman Nasional Siberut. 